\title{
Reduced specificity of autobiographical memory: A mediator between rumination and ineffective social problem-solving in major depression?
}

\author{
Filip Raes ${ }^{\mathrm{a}, *}$, Dirk Hermans ${ }^{\mathrm{a}}$, J. Mark G. Williams ${ }^{\mathrm{b}}$, Koen Demyttenaere ${ }^{\mathrm{c}}$, \\ Bernard Sabbe $^{\mathrm{d}}$, Guido Pieters ${ }^{\mathrm{e}}$, Paul Eelen ${ }^{\mathrm{a}}$ \\ ${ }^{a}$ Department of Psychology, University of Leuven, Tiensestraat 102, 3000 Leuven, Belgium \\ ${ }^{\mathrm{b}}$ Department of Psychiatry, University of Oxford, UK \\ ${ }^{\mathrm{c}}$ Department of Psychiatry, University Hospitals Gasthuisberg Leuven, Belgium \\ ${ }^{\mathrm{d} U n i v e r s i t y ~ o f ~ A n t w e r p ~ a n d ~ P s y c h i a t r i c ~ H o s p i t a l ~ S i n t-N o r b e r t u s, ~ D u f f e l, ~ B e l g i u m ~}$ \\ ${ }^{\mathrm{e}}$ University Centre Sint-Jozef, Kortenberg, Belgium
}

Received 3 September 2004; received in revised form 29 April 2005; accepted 4 May 2005

Available online 23 June 2005

\begin{abstract}
Background: Depressed individuals display a deficit in effectively solving social problem situations (e.g., [Marx, E.M., Williams, J.M.G., Claridge, G.C., 1992. Depression and social problem solving. J. Abnorm. Psychology 101, 78-86]). Recent research suggests that rumination may interfere with such effective problem-solving (e.g., [Watkins, E., Baracaia, S., 2002. Rumination and social problem-solving in depression. Behav. Res. Ther. 40, 1179-1189]). However, little is known, as yet, about the mechanisms that are underlying this relation between rumination and poor problem-solving. The present study investigated the role of reduced specificity of autobiographicial memories as a mediator of this relationship.

Methods: 24 depressed patients (15 women) completed the Autobiographical Memory Test (AMT), the Means-Ends ProblemSolving Task (MEPS), the Ruminative Response Scale (RRS) and the Rumination on Sadness Scale (RSS).

Results: Consistent with previous studies, rumination, ineffective problem-solving and reduced memory specificity were significantly associated. Regression analyses further extended these findings by showing that reduced memory specificity mediated the association between rumination and problem-solving effectiveness.

Limitations: The correlational nature of this study limits to some extent the conclusions that can be drawn on the directionality of the observed relationships.
\end{abstract}

\footnotetext{
* Corresponding author. Tel.: +32163258 92; fax: +32 16326099 .

E-mail address: filip.raes@psy.kuleuven.be (F. Raes).
} 
Conclusions: Results offer support for the idea that lack of autobiographical memory specificity mediates the known relationship between rumination and poor problem-solving.

(c) 2005 Elsevier B.V. All rights reserved.

Keywords: Depression; Autobiographical memory; Social problem-solving; Rumination

\section{Introduction}

Depressed individuals are known to suffer from deficits in social problem-solving. For example, compared to controls, depressed patients generate less effective strategies to hypothetical interpersonal problems (Goddard et al., 1996; Marx et al., 1992). Several studies suggest that rumination might be a factor, which impairs problem-solving in depression (e.g., Lyubomirsky and Nolen-Hoeksema, 1995; Watkins and Baracaia, 2002). Rumination can be defined as repetitive thoughts and behaviour that focus on one's symptoms of depression, and on the causes and consequences of these symptoms (Nolen-Hoeksema, 1991).

Recently, researchers have started to focus on the question why ruminators are poor problem-solvers (e.g., Lyubomirsky et al., 1999). The present study examines whether reduced specificity of autobiographical memory might be an underlying mechanism connecting rumination to poor problem-solving in depression. Williams reasoned that reduced memory specificity is likely to negatively impact problem-solving (e.g., Williams and Dritschel, 1988). This idea centers around the assumption that effective problem-solving requires access to specific memories (Evans et al., 1992; Williams, 1996). Numerous studies have shown that depressed people have difficulty retrieving such specific memories (Williams, 1996, 2004), using the Autobiographical Memory Test (AMT; Williams and Broadbent, 1986) in which respondents are requested to describe specific memories to cue words. A specific memory refers to an event that happened on a particular day (e.g., "that Sunday morning when my father told me that my grandmother had died"). When asked for such a specific memory, depressed people more often than controls tend to describe overgeneral memories instead of specific ones (e.g., "the times I fail to help someone").
Studies with depressed patients suggest that rumination maintains reduced specificity of memories (e.g., Watkins and Teasdale, 2001). Other studies suggest that reduced memory specificity interferes with problem-solving (e.g., Evans et al., 1992; Goddard et al., 1996; Pollock and Williams, 2001). However, the hypothesis that reduced memory specificity is a mediator between rumination and poor problemsolving has not been tested.

The aims of this study were (a) to examine the replicability of the associations between memory specificity, rumination and problem-solving, and (b) to investigate the hypothesis that memory specificity mediates the association between rumination and problem-solving.

\section{Methods}

\subsection{Participants}

Participants were 24 patients ( 15 women), all meeting criteria for current major depressive disorder (MDD; APA, 1994) on the Structured Clinical Interview for DSM-IV Axis-I Disorders (SCID-I; First et al., 1996; Van Groenestijn et al., 1999). Mean age was 39.04 years $($ S.D. $=11.04$, range $21-58)$.

\subsection{Materials}

\subsubsection{Autobiographical Memory Test (AMT)}

Participants are asked to recall a specific memory to 18 cue words: nine positive and nine negative, with positive and negative words alternating (De Decker et al., 2003; Williams and Broadbent, 1986). They are given $60 \mathrm{~s}$ for each cue. Each response is coded as either a specific memory or a nonspecific memory. Using this scoring procedure, previous studies obtained good reliability (Pousset et al., unpublished manuscript; Raes et al., 2003a). 


\subsubsection{Means-Ends Problem-Solving Task (MEPS)}

The MEPS (Platt and Spivack, 1975a; Spivack et al., 1981) was used to assess social problem-solving skills. Each story starts with the protagonist facing a problem, which is then followed by a successful ending. Participants are asked to describe strategies for solving the particular problem. An abbreviated format consisting of four stories was used (Marx et al., 1992; Platt and Spivack, 1975b). Effectiveness of responses was scored on a 7-point scale (not at all effective to extremely effective) (Marx et al., 1992). Total scores result from summing scores across all stories. A second rater scored the responses of a random sample of 12 participants. A correlation of $.86(p<.001)$ was found, suggesting good reliability.

\subsubsection{Ruminative Response Scale (RRS)}

The RRS (Nolen-Hoeksema and Morrow, 1991; Raes et al., 2003b) consists of 22 items measuring ruminative responses to depressed mood. Each item is rated on a 4-point scale (almost never to almost always).

\subsubsection{Rumination on Sadness Scale (RSS)}

The RSS (Conway et al., 2000; Raes et al., 2003b) is a 13-item questionnaire measuring rumination on sadness. Items are rated on a 5-point scale (not at all to very much). Because the scores on both rumination scales were highly correlated $(r=.80, p<.001)$, a composite rumination score was calculated by standardizing scores on each scale and then averaging the standardized scores.

\subsubsection{Beck Depression Inventory (BDI)}

The BDI (Beck et al., 1961; Bouman et al., 1985) is a self-rating measure for depressive symptoms.

\subsubsection{Letter-Number Sequencing (LNS)}

The LNS was used to measure working memory capacity (WAIS-III; Wechsler, 1997; Swets and Zeitlinger, 2000).

\subsection{Procedure}

Participants were tested individually. Testing was spread out over two sessions, with an interval of 1 to 2 days. Session 1 consisted of Informed Consent, SCID,
BDI, AMT, RRS and RSS. Session 2 consisted of the LNS and the MEPS.

\section{Results}

As predicted, memory specificity was negatively correlated with problem-solving effectivenesss (Table 1). The inverse relationships between rumination and both memory specificity and problem-solving were also replicated.

When controlled for rumination, memory specificity and MEPS effectiveness remained significantly correlated, partial $r=.52(p<.05)$, suggesting that this association is not simply a function of rumination. We then tested the mediational model, in which memory specificity is a mediator of the effects of rumination on MEPS effectiveness. To investigate mediation, we conducted three regression analyses, as recommended by Baron and Kenny (1986). First, memory specificity was regressed on rumination and was found to be significantly related to rumination, $t(22)=-2.76, p<.05$, $\beta=-.51$. Second, MEPS effectiveness was regressed on rumination and was also significantly related to rumination, $t(22)=-2.90, p<.01, \beta=-.53$. Third, MEPS effectiveness was regressed on both memory specificity and rumination. As hypothesized, rumination had no longer an effect on problem-solving effectiveness when controlled for memory specificity. Memory specificity was still a significant predictor of problem-solving effectiveness, $t(21)=2.77, p<.05$, $\beta=.51$, whereas rumination was reduced to nonsignificance, $t(21)=-1.45, p=.16, \beta=-.27$. This suggests that the relationship between rumination and ineffective problem-solving is mediated by decreased memory specificity.

Table 1

Means, standard deviations and zero-order correlations for AMT specificity, MEPS effectiveness and rumination

\begin{tabular}{lrccc}
\hline Variable & \multicolumn{1}{c}{$M$ (S.D.) } & 1 & 2 & 3 \\
\hline 1. AMT specificity & $9.67(3.12)$ & - & $.65^{* *}$ & $-.51^{*}$ \\
2. MEPS effectiveness & $16.38(3.37)$ & & - & $-.53^{* *}$ \\
3. Rumination & $0.00(1.00)$ & & & - \\
\hline
\end{tabular}

AMT specificity=number of specific first memories on the Autobiographical Memory Test, MEPS=Means-Ends Problem-Solving Task, Rumination $=$ Composite Rumination Measure.

$* p<.05$ (two-tailed).

$* * \quad p<.01$ (two-tailed). 
Partial correlations between MEPS effectiveness and memory specificity, controlling for depression severity (BDI) and for latency to respond to AMT cues, were significant, $r=.61(p<.01)$ and $r=.68(p<.001)$, respectively. This suggests that the relationship between memory specificity and MEPS effectiveness cannot be explained by mood or general unresponsiveness.

One might question whether it is not via a reduction of cognitive resources that rumination impacts problem-solving (Goddard et al., 1996). However, when MEPS effectiveness was regressed on rumination, memory specificity and working memory functioning (LNS), memory specificity was the only significant predictor of MEPS effectiveness, $t(19)=2.37, p<.05, \beta=.48$, whereas both rumination and working memory functioning were nonsignificant, $t(19)=-1.03, p=.31, \beta=-.21$ and $t(19)=.57$, $p<.58, \beta=.11$, respectively. ${ }^{1}$

\section{Discussion}

The present results replicated the finding that memory specificity is associated with effectiveness of social problem-solving and that this association is not a function of mood or general unresponsiveness (Evans et al., 1992; Goddard et al., 1996; Sidley et al., 1997). Additionally, the present results showed that this relationship could not be simply accounted for by capacity limitations in working memory or by people's natural tendency to ruminate. Rumination was also associated with both lack of memory specificity (Ramponi et al., 2004; Watkins and Teasdale, 2001) and ineffective problem-solving (Lyubomirsky and Nolen-Hoeksema, 1995; Watkins and Baracaia, 2002). Most important, mediational analyses supported the view of reduced memory specificity as a mediator or pathway through which rumination negatively affects problem-solving effectiveness. The results replicate the importance of rumination in explaining ineffective problem-solving in depression, but add to this that an important underlying mecha-

\footnotetext{
${ }^{1}$ Analyses with the working memory task (LNS) were performed on $n=23$, because one patient was not able to fluently cite the alphabet in correct order (which is a minimum requirement for taking the LNS).
}

nism by which rumination impairs problem-solving is reduced memory specificity.

An important limitation of the present study is its correlational nature. Thus, the degree to which cause and effect relationships can be inferred is limited. For assessing causation, experimental studies are preferred. For example, Williams, Eade and Wallace (in Williams, 2004; but see Goddard et al., 2001) showed that people who were induced to retrieve nonspecific memories generated less effective solutions to MEPS problems, compared to people who were induced to retrieve specific memories.

Note that we do not claim that reduced memory specificity is the only way through which rumination impairs problem-solving. There is more to solving a problem than the generation of effective solutions (D'Zurilla and Nezu, 1982). For example, MEPS protocols are not informative as to how willing respondents are to implement their solutions. It may be that rumination affects this aspect of problem-solving via depletion of individuals' motivation to carry out solutions (Lyubomirsky et al., 1999). Our study adds to this that rumination impacts another aspect of problemsolving, namely the generating of effective solutions, and that reduced memory specificity is an important way through which this impact occurs.

\section{Acknowledgements}

Filip Raes is Research Assistant of the Fund for Scientific Research-Flanders (Belgium). We thank Els Brunfaut, Luc Hamelinck, Sieglinde Meganck, Bart Jansen, Carmen De Grave and Stefaan Vertommen for their assistance in the recruitment of patients, and Evelien Coppens for her rating of the MEPS transcripts.

\section{References}

American Psychiatric Association, 1994. Diagnostic and Statistical Manual of Mental Disorders, 4th ed. Author, Washington, DC.

Baron, R.M., Kenny, D.A., 1986. The moderator-mediator variable distinction in social psychological research: conceptual, strategic, and statistical considerations. J. Pers. Soc. Psychol. 51, $1173-1182$.

Beck, A.T., Ward, C.H., Mendelson, M., Mock, J.E., Erbaugh, J.K., 1961. An inventory for measuring depression. Arch. Gen. Psychiatry $4,561-571$. 
Bouman, T.K., Luteijn, F., Albersnagel, F.A., Ploeg, F.A.E., van der, 1985. Enige ervaringen met de Beck Depression Inventory (Some experiences with the Beck Depression Inventory). Gedrag 13, 13-24.

Conway, M., Csank, P.A.R., Holm, S.L., Blake, C.K., 2000. On assessing individual differences in rumination on sadness. J. Pers. Assess. 75, 404-425.

De Decker, A., Hermans, D., Raes, F., Eelen, P., 2003. Autobiographical memory specificity and trauma in inpatient adolescents. J. Clin. Child Adolesc. Psychol. 32, 22-31.

D'Zurilla, T.J., Nezu, A., 1982. Social problem solving in adults. In: Kendall, P.C. (Ed.), Advances in Cognitive-Behavioral Research and Therapy, vol. 1. Academic Press, New York, pp. 201-274.

Evans, J., Williams, J.M.G., O’Loughlin, S., Howells, K., 1992. Autobiographical memory and problem-solving strategies of parasuicide patients. Psychol. Med. 22, 399-405.

First, M.B., Spitzer, R.L., Gibbon, M., Williams, J.B.W., 1996. Structured Clinical Interview for DSM-IV Axis I Disorders: Patient Edition (SCID-I/P, Version 2.0). American Psychiatric Press, Washington, DC.

Goddard, L., Dritschel, B., Burton, A., 1996. Role of autobiographical memory in social problem solving and depression. J. Abnorm. Psychology 105, 609-616.

Goddard, L., Dritschel, B., Burton, A., 2001. The effects of specific retrieval instruction on social problem-solving in depression. Br. J. Clin. Psychol. 40, 297-308.

Lyubomirsky, S., Nolen-Hoeksema, S., 1995. Effects of self-focused rumination on negative thinking and interpersonal problem solving. J. Pers. Soc. Psychol. 69, 190-276.

Lyubomirsky, S., Tucker, K.L., Caldwell, N.D., Berg, K., 1999. Why ruminators are poor problem solvers: clues from the phenomenology of dysphoric rumination. J. Pers. Soc. Psychol. $77,1041-1060$.

Marx, E.M., Williams, J.M.G., Claridge, G.C., 1992. Depression and social problem solving. J. Abnorm. Psychology 101, 78-86.

Nolen-Hoeksema, S., 1991. Responses to depression and their effects on the duration of depressive episodes. J. Abnorm. Psychology 100, 569-582.

Nolen-Hoeksema, S., Morrow, J., 1991. A prospective study of depression and posttraumatic stress symptoms after a natural disaster: the 1989 Loma Prieta earthquake. J. Pers. Soc. Psychol. $61,115-121$.

Platt, J.J., Spivack, G., 1975a. Manual for the Means-Ends Problem-Solving procedure (MEPS): a measure of interpersonal problem-solving skill. Philadelphia, Department of Mental Health Sciences, Hahnemann Medical College and Hospital.

Platt, J.J., Spivack, G., 1975b. Unidimensionality of the MeansEnds Problem-Solving (MEPS) procedure. J. Clin. Psychol. 31, 15-16.

Pollock, L.R., Williams, J.M.G., 2001. Effective problem solving in suicide attempters depends on specific autobiographical recall. Suicide Life-Threat. Behav. 31, 386-396.
Pousset, G., Raes, F., Hermans, D., unpublished manuscript. Correlates of autobiographical memory specificity in a non-clinical student population.

Raes, F., Hermans, D., de Decker, A., Eelen, P., Williams, J.M.G., 2003a. Autobiographical memory specificity and affect regulation: an experimental approach. Emotion 3, 201-206.

Raes, F., Hermans, D., Eelen, P., 2003b. De Nederlandstalige versie van de Ruminative Response Scale (RRS-NL) en de Rumination on Sadness Scale (RSS-NL) (The Dutch version of the Ruminative Response Scale (RRS-NL) and the Rumination on Sadness Scale (RSS-NL)). Gedragstherapie 36, 97-104.

Ramponi, C., Barnard, P.J., Nimmo-Smith, I., 2004. Recollection deficits in dysphoric mood: an effect of schematic models and executive mode? Memory 12, 655-670.

Sidley, G.L., Whitaker, K., Calam, R.M., Wells, A., 1997. The relationship between problem-solving and autobiographical memory in parasuicide patients. Behav. Cogn. Psychother. 25, $195-202$.

Spivack, G., Shure, M.B., Platt, J.J., 1981. Means-Ends Problem Solving: Stimuli and Scoring Procedures Supplement. Philadelphia, Department of Mental Health Sciences, Hahnemann Medical College and Hospital.

Swets, Zeitlinger, 2000. Handleiding bij de Nederlandse bewerking van de WAIS-III (Manual of the Dutch version of the WAIS-III). Author, Lisse, The Netherlands.

Van Groenestijn, M.A.C., Akkerhuis, G.W., Kupka, R.W., Schneider, N., Nolen, W.A., 1999. Gestructureerd Klinisch Interview voor de vaststelling van DSM-IV As I Stoornissen (Structured Clinical Interview for DSM-IV Axis I Disorders). Swets and Zeitlinger, Lisse, The Netherlands.

Watkins, E., Baracaia, S., 2002. Rumination and social problemsolving in depression. Behav. Res. Ther. 40, 1179-1189.

Watkins, E., Teasdale, J.D., 2001. Rumination and overgeneral memory in depression: effects of self-focus and analytic thinking. J. Abnorm. Psychology 110, 353-357.

Wechsler, D., 1997. Wechsler Adult Intelligence Scale, third edition. The Psychological Corporation, San Antonio, TX.

Williams, J.M.G., 1996. Depression and the specificity of autobiographical memory. In: Rubin, D.C. (Ed.), Remembering Our Past: Studies in Autobiographical Memory. Cambridge University Press, Cambridge, UK, pp. 244-267.

Williams, J.M.G., 2004. Experimental cognitive psychology and clinical practice: autobiographical memory as a paradigm case. In: Yiend, J. (Ed.), Cognition, Emotion and Psychopathology. Cambridge University Press, Cambridge, UK, pp. 251-269.

Williams, J.M.G., Broadbent, K., 1986. Autobiographical memory in suicide attempters. J. Abnorm. Psychology 95, 144-149.

Williams, J.M.G., Dritschel, B., 1988. Emotional disturbance and the specificity of autobiographical memory. Cogn. Emot. 2, 221-234. 